\title{
Effect of Pt Particle Size and Phosphorous Addition on Furfural Hydrogenation Over $\mathrm{Pt} / \mathrm{Al}_{2} \mathrm{O}_{3}$
}

\author{
Miren Agote-Arán ${ }^{1} \cdot$ Shahram Alijani ${ }^{2} \cdot$ Chiara Coffano $^{1,3} \cdot$ Alberto Villa $^{2} \cdot$ Davide Ferri $^{1}$
}

Received: 22 March 2021 / Accepted: 27 May 2021 / Published online: 11 June 2021

(C) The Author(s) 2021

\begin{abstract}
$\mathrm{Pt} / \mathrm{Al}_{2} \mathrm{O}_{3}$ catalysts with different Pt particle sizes and after phosphorous deposition were studied for liquid phase catalysed furfural hydrogenation. The activity and selectivity were related to various physico-chemical properties studied by scanning transmission electron microscopy, $\mathrm{N}_{2}$ physisorption, ${ }^{31} \mathrm{P}$ nuclear magnetic resonance, diffuse reflectance Fourier transform infrared spectroscopy and attenuated total reflectance infrared spectroscopy. The results indicate that the large particles obtained upon calcination of $1 \mathrm{wt} \% \mathrm{Pt}_{2} \mathrm{Al}_{2} \mathrm{O}_{3}$ at $600{ }^{\circ} \mathrm{C}$ exhibited higher turnover frequency per surface $\mathrm{Pt}$; nonetheless, the overall activity decreased due to the loss of surface Pt upon sintering. While in certain cases phosphorous can act as promoter, the addition of this element to $\mathrm{Pt} / \mathrm{Al}_{2} \mathrm{O}_{3}$ resulted in catalyst poisoning, which was ascribed to Pt encapsulation/blockage effects related to formation of $\mathrm{AlPO}_{4}$. Finally, gradual deactivation of $\mathrm{Pt} / \mathrm{Al}_{2} \mathrm{O}_{3}$ was observed over five consecutive catalytic cycles which was caused by Pt sintering (from 0.6 to $2.0 \mathrm{~nm}$ ) as well as by irreversible adsorption of organic reaction intermediates.
\end{abstract}

\section{Graphic Abstract}

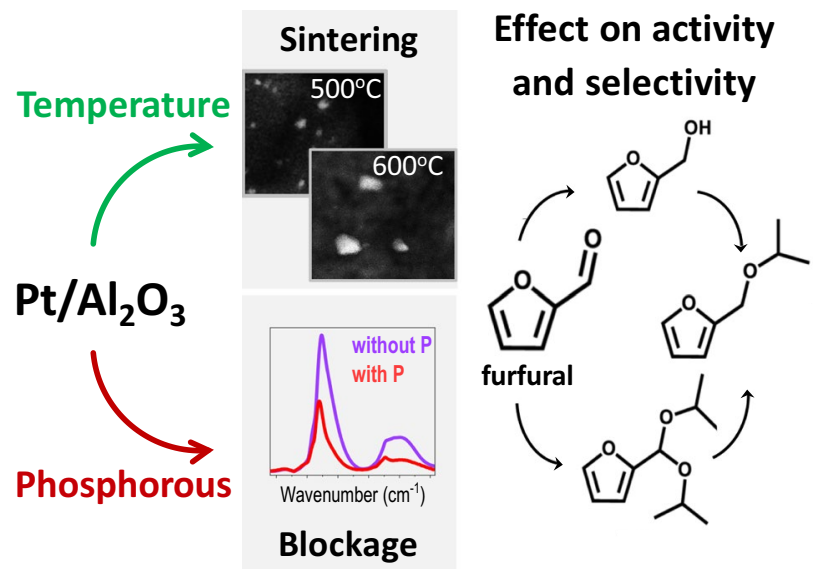

Keywords Furfural hydrogenation $\cdot \mathrm{Pt} / \mathrm{Al}_{2} \mathrm{O}_{3} \cdot$ Phosphorous $\cdot$ Deactivation

Davide Ferri

davide.ferri@psi.ch

Paul Scherrer Institut, 5232 Villigen, Switzerland

2 Dipartimento di Chimica, Università degli Studi di Milano, 20133 Milan, Italy

3 Dipartimento di Energia, Politecnico di Milano, 20156 Milan, Italy

\section{Introduction}

Alternative energy sources, such as biomass-based compounds, are attracting significant attention to meet the rising demand for fine chemicals while minimising the harm to the environment $[1,2]$. Polysaccharide hemicellulose from waste lignocellulosic biomass is one example, where furfural can be obtained by acid-catalysed hydrolysis and dehydration $[3,4]$. Furfural is considered one of the most important 
biomass-derived chemicals as it is the precursor of versatile and valued derivatives [5]. Furfural can be converted to furfuryl alcohol (FA) and tetrahydrofurfuryl alcohol (THFA) through selective catalytic hydrogenation (Scheme 1) [6]. FA is especially desirable due to its use in the polymer and fine chemical industries including the manufacture of resins, vitamin $\mathrm{C}$, dispersants, lysine, and lubricants $[4,7]$. THFA is primarily used as an environmentally friendly solvent since it is degradable, less toxic, and far more stable than unsaturated furan compounds [2, 8, 9]. By-products are also obtained depending on the reaction conditions. For example, when using 2-propanol as the solvent, the formation of acetals has been proposed which is followed by hydrolysis to furfuryl ether (FIE) [10]. The major challenge of furfural hydrogenation is the control of the hydrogenation of $\mathrm{C}=\mathrm{C}$ or $\mathrm{C}=\mathrm{O}$ bonds over secondary reaction pathways-e.g. ether by-product formation-using a highly selective catalyst [1, 4]. In this regard, a variety of heterogeneous catalysts have been employed for selective furfural hydrogenation including supported $\mathrm{Pt} \mathrm{[11],} \mathrm{Pd}$ [12], $\mathrm{Ru}$ [13], $\mathrm{Cu}$ [14], and $\mathrm{Ni}$ [15]. In particular, $\mathrm{Pt}$ supported on $\mathrm{SiO}_{2}, \mathrm{TiO}_{2}$, and $\mathrm{Al}_{2} \mathrm{O}_{3}$ has gained interest as $\mathrm{Pt}$ promotes the selective hydrogenation of the $\mathrm{C}=\mathrm{O}$ bond yielding FA $[12,16]$. Srinivas et al. reported a selectivity of $99 \%$ at $65 \%$ of furfural conversion on $10 \mathrm{wt} \%$ $\mathrm{Pt} / \gamma-\mathrm{Al}_{2} \mathrm{O}_{3}$ at $25^{\circ} \mathrm{C}$; however, the high $\mathrm{Pt}$ loading and $\mathrm{H}_{2}$ pressures of 60 bar used represent major drawbacks [12].

Studies on different catalyst formulations suggest that activity towards furfural hydrogenation can be affected by noble metal particle size. For example, Barria et al. [17] associated differences in the catalytic activity of Ru-based materials to their particle size, with small $\mathrm{Ru}$ particles $(1.3-1.8 \mathrm{~nm})$ leading to higher catalytic activity and selectivity to FA. The selectivity to various products has been reported to be particle size dependent also in Pd-based catalysts $[4,6]$. Some reports in Pt-based catalysts using particles between 1.6 and ca. $36 \mathrm{~nm}$ suggest no apparent correlation between noble metal particle size and selectivity in

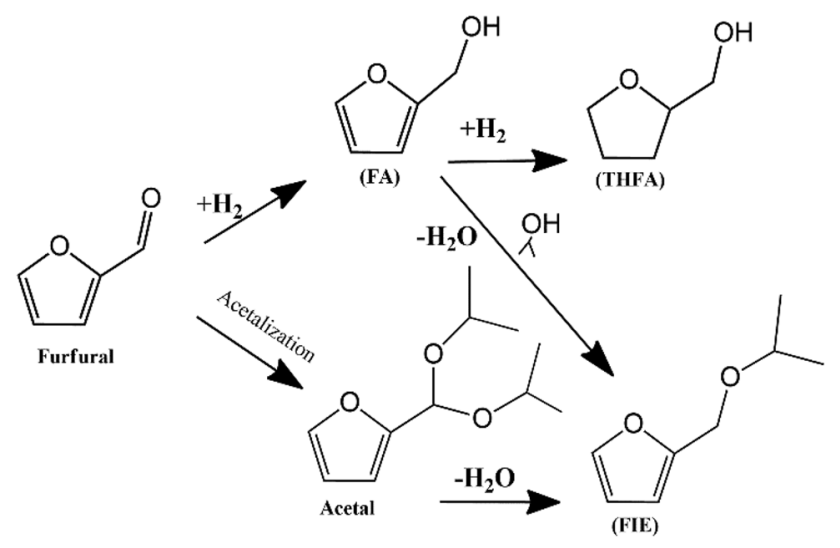

Scheme 1 Reaction routes during furfural hydrogenation liquid phase hydrogenation conditions [1, 18, 19, 20]; nonetheless, Tylor et al. [16] claimed that Pt particles smaller than ca. $4 \mathrm{~nm}$ promote the selective decarbonylation to furan. Similar observation was made by Pushkarev et al. [21] for PVP encapsulated Pt supported on mesoporous silica in the vapour phase reaction for Pt particles smaller than $2 \mathrm{~nm}$.

The modification of metal-supported catalysts by strongly adsorbed organic compounds such as phosphorous (P) can also affect their activity and selectivity [22-24]. The promoting effect of $\mathrm{P}$ in Pd nanoparticles was observed in the liquid-phase hydrogenation of $o$-chloronitrobenzene, which was attributed to an increased electron density of the $\operatorname{Pd}(0)$ clusters in the Pd-P catalyst compared to P-free metallic Pd [23]. Similarly, we have reported a promotion of Ru reducibility by $\mathrm{P}$, which was accompanied by the formation of Brønsted acid sites. After reduction, the P-based catalyst was more active for catalytic transfer hydrogenation of furfural and more stable against Ru leaching [24]. The addition of $\mathrm{P}$ to transition metal catalysts has also been reported to increase activation energies for $\mathrm{C}=\mathrm{C}$ and $\mathrm{C}=\mathrm{O}$ bonds in hydrodeoxygenation (HDO) reactions, e.g. dehydrogenation of isobutane [25]. The variations in catalytic activity caused by the addition of $\mathrm{P}$ are also ascribed to strong differences in adsorption energies and the prevalent binding modes of organic molecules on surfaces [26]. On the other hand, it has been reported that such modifiers can act as poisons; for example, Mallat et al. [22] reported improved selectivity in the oxidation of L-sorbose by modification of $\mathrm{Pt} / \mathrm{Al}_{2} \mathrm{O}_{3}$ with phosphines, while the rate of reaction decreased based on the phosphine/Pt ratio due to blocking of $\mathrm{Pt}$ active sites.

In this work, a series of $\mathrm{Pt} / \mathrm{Al}_{2} \mathrm{O}_{3}$ catalysts was prepared aiming for low metal loading (1 wt\%) with high dispersion. Subsequently, different thermal treatments were carried out to induce sintering and to explore the effect of particle size. Phosphorous was also added to pristine $\mathrm{Pt} / \mathrm{Al}_{2} \mathrm{O}_{3}$ to identify possible promotion effects. Finally, the durability of $\mathrm{Pt} / \mathrm{Al}_{2} \mathrm{O}_{3}$ was investigated over five consecutive furfural hydrogenation cycles and the causes of catalyst deterioration were identified.

\section{Experimental}

\subsection{Synthesis}

$\mathrm{Pt} / \mathrm{Al}_{2} \mathrm{O}_{3}$ was prepared by incipient wetness impregnation of $\gamma-\mathrm{Al}_{2} \mathrm{O}_{3}$ (PURALOX, SCFa-140, Sasol) with tetraammineplatinum (II) nitrate (ABCR, 99\% purity) to achieve a $\mathrm{Pt}$ loading of ca. $1 \mathrm{wt} \%$. After drying at $120^{\circ} \mathrm{C}$ overnight, the sample was calcined in air in a static oven at $500{ }^{\circ} \mathrm{C}$ for $4 \mathrm{~h}$ $\left(2{ }^{\circ} \mathrm{C} / \mathrm{min}\right.$ ramp). The resulting powder was divided into six portions, which were subjected to the following treatments (Scheme 2): 
a) pristine $\left(\mathrm{Al}_{2} \mathrm{O}_{3}-\mathrm{Pt}\right)$ with no further treatments;

b) second calcination at $500{ }^{\circ} \mathrm{C}\left(\mathrm{Al}_{2} \mathrm{O}_{3}-\mathrm{Pt}-500\right)$;

c) second calcination at $600{ }^{\circ} \mathrm{C}\left(\mathrm{Al}_{2} \mathrm{O}_{3}-\mathrm{Pt}-600\right)$;

d) incipient wetness impregnation of $\mathrm{P}$ (2 wt\%) using a solution of ammonium dihydrogen phosphate $(99 \%$ purity, Fluka) followed by drying and calcination at $500{ }^{\circ} \mathrm{C}$ for $4 \mathrm{~h}\left(\mathrm{Al}_{2} \mathrm{O}_{3}-\mathrm{Pt}-2 \mathrm{P}\right)$;

e) durability tests by performing five consecutive reaction cycles $\left(\mathrm{Al}_{2} \mathrm{O}_{3}-\mathrm{Pt}-\mathrm{Used}\right)$.

The second calcination at $500{ }^{\circ} \mathrm{C}$ (sample b) was carried out to compare particle sizes with the sample obtained after treatments d.

\subsection{Catalytic Activity}

All samples were tested for the liquid phase hydrogenation of furfural (purity 99\%, Sigma-Aldrich) in a typical solvent for this reaction, 2-propanol. The reaction was carried out at $150{ }^{\circ} \mathrm{C}$ in a stainless-steel reactor (30 mL capacity), equipped with a heater, a magnetic stirrer, and thermometer. For each experiment, $58 \mathrm{mg}$ of a catalyst (1:1000 metal/ substrate) and $10 \mathrm{~mL}$ of furfural solution (0.3 $\mathrm{M}$ in 2-propanol) were loaded into the autoclave. The autoclave was purged three times with $\mathrm{N}_{2}$ before switching to pressurized $\mathrm{H}_{2}$ (5 bar). The reactor was heated to $150{ }^{\circ} \mathrm{C}$ and the reaction started as soon as the stirring speed was set to $1200 \mathrm{rpm}$.

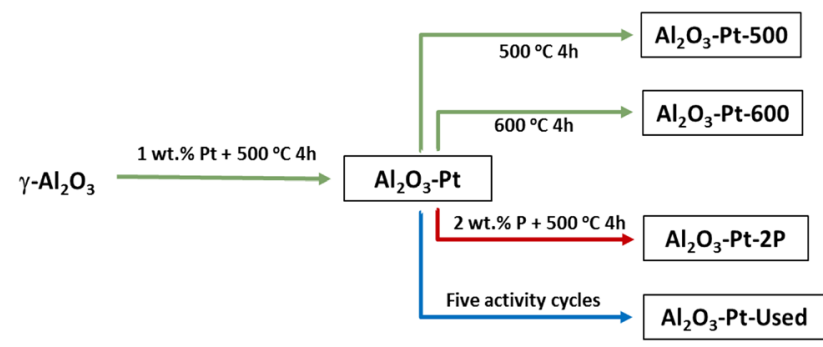

Scheme 2 Schematic representation of the synthesis approach for the Pt-based catalysts prepared
After the reaction was completed, the stirring was halted and the reaction was quenched to room temperature by immersing the autoclave in an ice bath for ca. $2 \mathrm{~min}$. An aliquot of the reaction mixture $(500 \mu \mathrm{L})$ was collected and centrifuged to separate the liquid reaction mixture, which was analysed using an Agilent gas chromatograph (Agilent 6890) equipped with a Zebron ZB5 $60 \mathrm{~m} \times 0.32 \mathrm{~mm} \times 1 \mu \mathrm{m}$ column and a FID detector. The temperature programme used was $2 \mathrm{~min}$ at $100{ }^{\circ} \mathrm{C}, 15^{\circ} \mathrm{C} \mathrm{min}{ }^{-1}$ up to $170{ }^{\circ} \mathrm{C}$ with a hold time of $2 \mathrm{~min}$ at $170{ }^{\circ} \mathrm{C}, 20^{\circ} \mathrm{C} \mathrm{min}^{-1}$ up to $300^{\circ} \mathrm{C}$ with a final hold time of $3 \mathrm{~min}$. Response factors of the furfural and products (FA, THFA, and FA-ether) were calculated using a known concentration of standard solutions of the pure compounds, using 1-dodecanol as external standard. The performance of each sample was measured after 15, 60,180 and $300 \mathrm{~min}$ of reaction. The activity $\left(\mathrm{h}^{-1}\right)$ reported in Table 1 corresponds to the aliquots taken after $15 \mathrm{~min}$ of reaction as $\mathrm{mol}_{\text {converted }} \bullet \mathrm{mol}_{\text {metal }}{ }^{-1} \bullet \mathrm{h}^{-1}$. The selectivity in Table 1 corresponds to aliquots at ca. $50 \%$ furfural conversion, more precisely at 53, 46, 52, 58\% conversion for $\mathrm{Al}_{2} \mathrm{O}_{3}-\mathrm{Pt}, \mathrm{Al}_{2} \mathrm{O}_{3}-\mathrm{Pt}-500, \mathrm{Al}_{2} \mathrm{O}_{3}-\mathrm{Pt}-600$ and $\mathrm{Al}_{2} \mathrm{O}_{3}-\mathrm{Pt}-2 \mathrm{P}$, respectively.

The durability of pristine $\mathrm{Al}_{2} \mathrm{O}_{3}-\mathrm{Pt}$ was probed by performing five consecutive activity tests under the conditions described above. After each activity run, the catalyst recovered by filtration was reused in the following run without any further treatment. The liquid phase was analysed by inductively coupled plasma optical emission spectroscopy (ICP-OES). The catalyst recovered after the five consecutive cycles is referred to as $\mathrm{Al}_{2} \mathrm{O}_{3}-\mathrm{Pt}$-used.

\subsection{Characterisation}

The poisons content on the samples was determined by inductively coupled plasma optical emission spectrometry (ICP-OES) using a Varian Vista AX spectrometer. The samples were dissolved in a $\mathrm{HF} / \mathrm{HCl} / \mathrm{HNO}_{3}$ mixture. All calibration solutions were prepared using $99.999 \%$ pure commercial standards. The average of atomic emission lines of three

Table 1 Elemental analysis (ICP-OES), specific surface area, Pt particle size and catalytic activity as well as selectivity of Pt-based catalysts

\begin{tabular}{|c|c|c|c|c|c|c|c|c|c|c|}
\hline \multirow[t]{2}{*}{ Catalyst } & \multirow[t]{2}{*}{ Av. $\mathrm{Pt}$ size $(\mathrm{nm})$} & \multirow[t]{2}{*}{ Content Pt/P (wt\%) } & \multirow[t]{2}{*}{$\mathrm{SA}_{\mathrm{BET}}\left(\mathrm{m}^{2} / \mathrm{g}\right)$} & \multicolumn{4}{|c|}{ Selectivity $(\%)^{\mathrm{a}}$} & \multirow[t]{2}{*}{$\mathrm{C}$ balance $(\%)$} & \multirow[t]{2}{*}{ Activity $\left(\mathrm{h}^{-1}\right)^{\mathrm{b}}$} & \multirow[t]{2}{*}{$\operatorname{TOF}\left(\mathrm{h}^{-1}\right)^{\mathrm{c}}$} \\
\hline & & & & FA & THFA & FIE & Acetal & & & \\
\hline $\mathrm{Al}_{2} \mathrm{O}_{3}-\mathrm{Pt}$ & $0.6 \pm 0.2$ & $0.99 /-$ & 160.8 & 98.5 & - & - & 1.5 & 100 & 1087 & 1087 \\
\hline $\mathrm{Al}_{2} \mathrm{O}_{3}-\mathrm{Pt}-500$ & $1.2 \pm 0.3$ & - & 160.2 & 96.5 & - & - & 3.5 & 101 & 883 & 1766 \\
\hline $\mathrm{Al}_{2} \mathrm{O}_{3}-\mathrm{Pt}-600$ & $25.2 \pm 16.3$ & - & 160.9 & 94.6 & - & 1.1 & 4.2 & 101 & 640 & 26,666 \\
\hline $\mathrm{Al}_{2} \mathrm{O}_{3}-\mathrm{Pt}-2 \mathrm{P}$ & $1.1 \pm 0.9$ & $0.98 / 2.14$ & 134.8 & 91.9 & - & 5.2 & 2.9 & 100 & 377 & 690 \\
\hline
\end{tabular}

Reaction conditions: furfural $0.3 \mathrm{M}$ in isopropanol, metal/substrate $1: 1000,5$ bar of $\mathrm{H}_{2} .150{ }^{\circ} \mathrm{C}$

${ }^{\mathrm{a}}$ Calculated at ca. $50 \%$ of conversion

${ }^{\mathrm{b}}$ Calculated after $15 \mathrm{~min}$ of reaction as $\mathrm{mol}_{\text {converted }} \cdot \mathrm{mol}_{\mathrm{PtTotal}^{-1}} \cdot \mathrm{h}^{-1}$

${ }^{\mathrm{c}}$ Calculated after $15 \mathrm{~min}$ of reaction as $\mathrm{mol}_{\text {converted }} \cdot \mathrm{mol}_{\mathrm{PtSurf}}{ }^{-1} \cdot \mathrm{h}^{-1}$ 
measurements was used to determine the concentration of the elements of interest.

Nitrogen physisorption was measured at $-196{ }^{\circ} \mathrm{C}$ using a Quantachrome Autosorb-1 instrument. The sample (ca. $150 \mathrm{mg}$ ) was outgassed overnight at $350{ }^{\circ} \mathrm{C}$ under high vacuum prior to the sorption measurement. The Brunauer-Emmett-Teller (BET) equation was used to calculate the specific surface area.

Solid-state ${ }^{31} \mathrm{P}$ magic angle spinning (MAS) NMR measurements were performed on a Bruker Avance III 400 NMR spectrometer (Bruker Biospin AG, Fällanden, Switzerland) using a $2.5 \mathrm{~mm}$ CP-MAS probe at ambient temperature. Data was recorded at the same rotation rate with $2.0 \mu \mathrm{s}$ $\left(90^{\circ}\right)$ pulses and $5 \mathrm{~s}$ relaxation delays applying TPPM 15 decoupling of $66 \mathrm{kHz}$ on ${ }^{1} \mathrm{H}$ during acquisition. The chemical shifts were referenced externally to solid $\mathrm{NH}_{4} \mathrm{H}_{2} \mathrm{PO}_{4}$ at $0.0 \mathrm{ppm}$.

For scanning transmission electron microscopy (STEM), the samples were finely ground in an agate mortar and suspended in ethanol before depositing a drop of the suspension on a copper grid coated with a holey carbon film. Highangle annular dark-field (HAADF) images were recorded at an acceleration voltage of $300 \mathrm{kV}$ on a FEI Technai F30 FEG scanning transmission electron microscope equipped with super twin lens and Schottky type emitter. From the electron micrographs of each sample, the particle sizes of at least 200 noble metal particles were evaluated using ImageJ software [27]. The particles observed had a close to spherical shape, the diameter of such spheres was taken as the particle size. Using OriginLab software, the particle diameters were then grouped into evenly spaced bins ranging from 1 to $35 \mathrm{~nm}$, with 20 bins per factor of 2.5 change in dimension. The number of surface Pt available for reaction was calculated taking into account the amount of Pt on the sample and the average particle radius ( $r$ ) while assuming hemispherical $\mathrm{Pt}$ particle shape [28]. The Pt volume $\left(\mathrm{V}_{\mathrm{Pt}}\right)$ per catalyst unit gram was calculated from the Pt density $\left(\rho_{\mathrm{Pt}}=2.145 \times 10^{-23}\right.$ $\left.\mathrm{gPt} / \AA^{3}\right)[28]$ and the Pt weight fraction $\left(\mathrm{W}_{\mathrm{Pt}}\right)$ :

$\mathrm{V}_{\mathrm{Pt}}=\mathrm{W}_{\mathrm{Pt}} / \mathrm{r}_{\mathrm{Pt}}$

Then, the moles of surface Pt per catalyst unit gram $\left(\mathrm{Mol}_{\mathrm{Pt.S}}\right)$ were calculated using the cross-sectional area of atomic $\mathrm{Pt}\left(\mathrm{A}_{\mathrm{Pt}, \mathrm{X}} ; 8.0 \AA^{2}[28]\right)$

$\mathrm{Mol}_{\mathrm{Pt} . \mathrm{S}}=\left(\mathrm{A}_{\mathrm{Pt}, \mathrm{P}} *\left(\mathrm{~V}_{\mathrm{Pt}} / \mathrm{V}_{\mathrm{Pt}, \mathrm{p})}\right) /\left(\mathrm{A}_{\mathrm{Pt}, \mathrm{X}} * \mathrm{NA}\right)\right.$

where NA is the Avogadro number, and $\mathrm{A}_{\mathrm{Pt}, \mathrm{P}}$ and $\mathrm{V}_{\mathrm{Pt}, \mathrm{P}}$ are the area and volume of one Pt particle of the sample (considering average particle size).

Diffuse reflectance infrared Fourier transform spectroscopy (DRIFTS) experiments of CO adsorption were performed on a VERTEX 70 FT-IR spectrometer (Bruker Optics) equipped with a diffuse reflectance accessory
(Praying Mantis, Harrick) and a liquid nitrogen cooled MCT detector. All samples were pre-treated in $3 \mathrm{vol} \% \mathrm{H}_{2} /$ $\operatorname{Ar}(50 \mathrm{ml} / \mathrm{min})$ at $300{ }^{\circ} \mathrm{C}$ for $30 \mathrm{~min}$, cooled to room temperature and purged with Ar flow for few minutes prior to acquisition of the background spectrum. Then, $\mathrm{CO}$ adsorption $\left(5 \mathrm{vol} \% \mathrm{CO} / \mathrm{Ar}, 50 \mathrm{ml} / \mathrm{min}\right.$ ) was carried out at $25{ }^{\circ} \mathrm{C}$ for $50 \mathrm{~min}$. Spectra were recorded by co-adding 100 scans at a resolution of $4 \mathrm{~cm}^{-1}$ and $10 \mathrm{~Hz}$ scanner velocity. Using the same spectrometer, ATR-IR spectra were recorded by coadding 100 scans at $4 \mathrm{~cm}^{-1}$ resolution at room temperature using a Platinum ATR unit (Bruker). No pretreatment of the samples was carried out. All IR data were processed using the OriginLab software.

$\mathrm{H}_{2}$ Temperature-Programmed Reduction $\left(\mathrm{H}_{2}\right.$-TPR) measurements were carried out after sample pretreatment in $\mathrm{Ar}$ at $360{ }^{\circ} \mathrm{C}$ for $30 \mathrm{~min}$. After cooling to room temperature, the gas flow was changed to $10 \mathrm{vol} \% \mathrm{H}_{2}$ in Ar and the sample $(0.3 \mathrm{~g})$ was heated to $800{ }^{\circ} \mathrm{C}$ at $5{ }^{\circ} \mathrm{C} / \mathrm{min}$. The consumption of $\mathrm{H}_{2}$ during the temperature ramp was monitored with a TCD detector.

\section{Results and Discussion}

\subsection{Characterisation}

To evaluate the effects of particle size and addition of phosphorous $(\mathrm{P})$ on furfural hydrogenation, the samples studied consisted of: (1) pristine $\mathrm{Pt} / \mathrm{Al}_{2} \mathrm{O}_{3}\left(\mathrm{Al}_{2} \mathrm{O}_{3}-\mathrm{Pt}\right)$ prepared by impregnation and followed by calcination at $500{ }^{\circ} \mathrm{C}$, (2) a catalyst obtained after a second calcination of the pristine sample at $500{ }^{\circ} \mathrm{C}\left(\mathrm{Al}_{2} \mathrm{O}_{3}-\mathrm{Pt}-500\right)$; (3) a catalyst obtained after a second calcination of the pristine sample at $600{ }^{\circ} \mathrm{C}$ $\left(\mathrm{Al}_{2} \mathrm{O}_{3}-\mathrm{Pt}-600\right)$ and (4) a catalyst obtained after addition of $2 \mathrm{wt} \% \mathrm{P}$ to the pristine sample followed by calcination at $500{ }^{\circ} \mathrm{C}\left(\mathrm{Al}_{2} \mathrm{O}_{3}-\mathrm{Pt}-2 \mathrm{P}\right)$.

Table 1 shows the results of specific surface area (SA) and average noble metal particle size (derived from TEM images) for the samples. Chemical analysis of selected samples is also included to illustrate that the selected synthesis method led to expected values of $\mathrm{Pt}$ and $\mathrm{P}$ contents. The TEM image analysis (Fig. 1; Table 1) indicates that $\mathrm{Al}_{2} \mathrm{O}_{3}-\mathrm{Pt}$ possessed high Pt dispersion with narrow particle size distribution and average particle size of $0.6 \mathrm{~nm}$; such high dispersion is desirable to ensure high furfural hydrogenation performance. As expected, the samples calcined a second time exhibited an increased average particle size of 1.2 and $25 \mathrm{~nm}$ for $\mathrm{Al}_{2} \mathrm{O}_{3}-\mathrm{Pt}-500$ and $\mathrm{Al}_{2} \mathrm{O}_{3}-\mathrm{Pt}-600$, respectively. As noted above, $\mathrm{Al}_{2} \mathrm{O}_{3}-\mathrm{Pt}-2 \mathrm{P}$ undergoes two calcinations, i.e. after $\mathrm{Pt}$ and $\mathrm{P}$ impregnations. In line, the resulting particle size $(1.1 \mathrm{~nm})$ was comparable to that of $\mathrm{Al}_{2} \mathrm{O}_{3}-\mathrm{Pt}-500(1.2 \mathrm{~nm})$, which was treated twice at $500{ }^{\circ} \mathrm{C}$. 

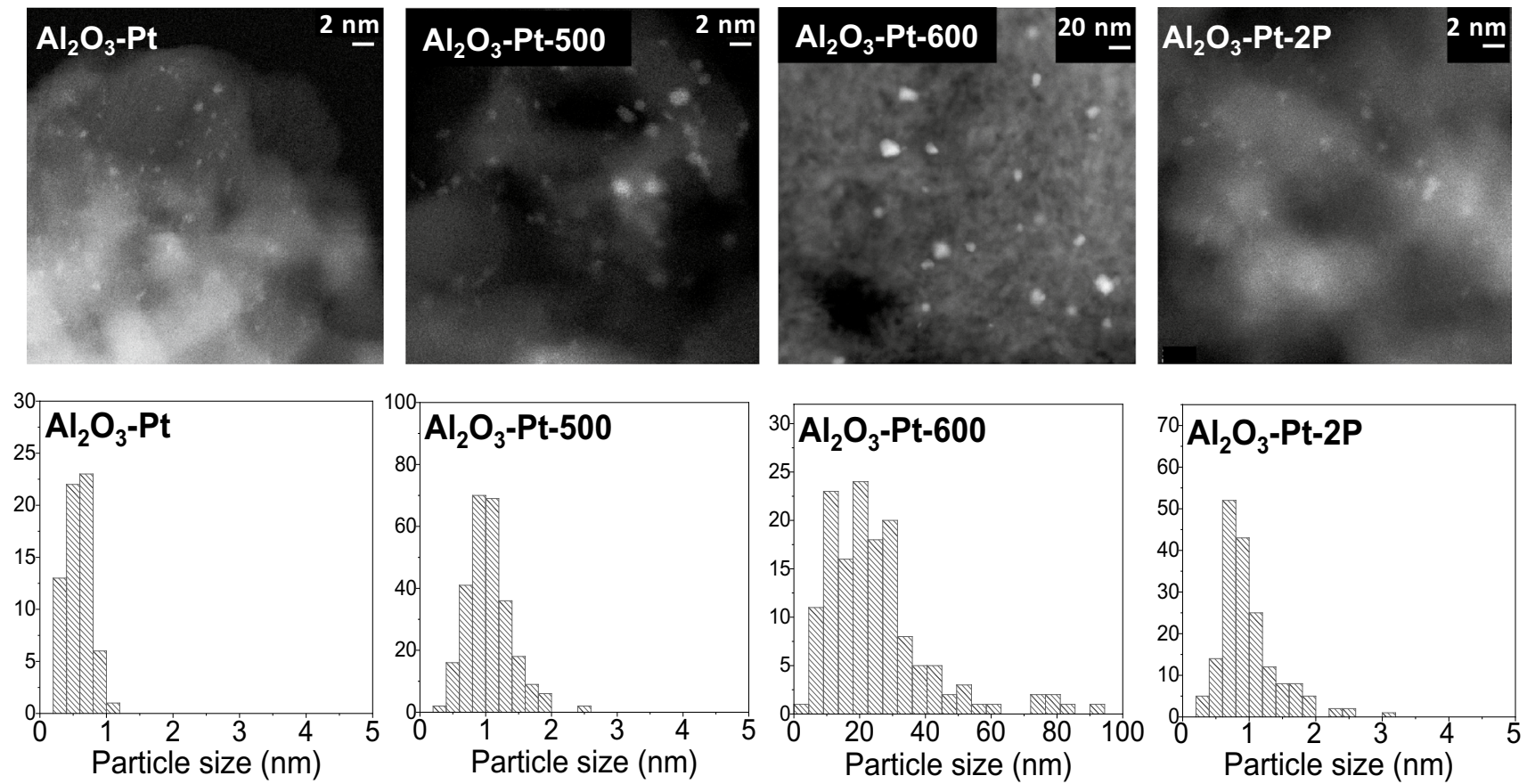

Fig. 1 Selected HAADF-STEM images (top) and the corresponding particle size distribution (bottom) for the Pt-based catalysts

Pristine $\mathrm{Al}_{2} \mathrm{O}_{3}-\mathrm{Pt}$ exhibited a SA of $161 \mathrm{~m}^{2} / \mathrm{g}$ and further calcinations up to $600{ }^{\circ} \mathrm{C}$ did not induce significant changes in this value. The $\mathrm{P}$ modification however resulted in a SA decrease to $135 \mathrm{~m}^{2} / \mathrm{g}$. This decrease was attributed to pore blockage upon interaction of $\mathrm{P}$ with the $\mathrm{Al}_{2} \mathrm{O}_{3}$ support. ${ }^{31} \mathrm{P}$ NMR spectra of $\mathrm{Al}_{2} \mathrm{O}_{3}-\mathrm{Pt}-2 \mathrm{P}$ exhibited signals typically ascribed to the $\mathrm{AlPO}_{4}$ phase with a broad peak between 0 and -40 ppm (Fig. 2a) [29].

$\mathrm{H}_{2}$-TPR of $\mathrm{Al}_{2} \mathrm{O}_{3}-\mathrm{Pt}-500$ and $\mathrm{Al}_{2} \mathrm{O}_{3}-\mathrm{Pt}-2 \mathrm{P}$, which comprised comparable particle size indicated that Pt redox properties also changed upon P addition (Fig. 2b). Both samples exhibited a broad $\mathrm{H}_{2}$ consumption peak between 300 and $600{ }^{\circ} \mathrm{C}$ corresponding to reduction of PtOx particles strongly interacting with the support [30]. While $\mathrm{Al}_{2} \mathrm{O}_{3}-\mathrm{Pt}-500$ presented a maximum of reduction at $392{ }^{\circ} \mathrm{C}, \mathrm{Al}_{2} \mathrm{O}_{3}-\mathrm{Pt}-2 \mathrm{P}$ displayed it at $420{ }^{\circ} \mathrm{C}$ pointing to a difficulty to reduce the noble metal in the presence of $\mathrm{P}$. Additionally, the higher $\mathrm{H}_{2}$ consumption peak for $\mathrm{Al}_{2} \mathrm{O}_{3}-\mathrm{Pt}-2 \mathrm{P}$ can be ascribed to the fact that the presence of $\mathrm{P}$ increased the fraction of $\mathrm{PtOx}$ in the catalyst. The small reduction peaks at temperatures above $600{ }^{\circ} \mathrm{C}$ correspond likely to reduction of the $\mathrm{Al}_{2} \mathrm{O}_{3}$ support [31].

These TPR results are opposed to reports on $\mathrm{Pd}$ and $\mathrm{Ru}$ were the presence of $\mathrm{P}$ resulted in increased electron density and reducibility [24, 26]. However, recent studies devoted to investigate poisoning effects also observed a decrease of reducibility in similar Pt-based samples in the presence of $\mathrm{P}[31,32]$.
Fig. 2 a ${ }^{31} \mathrm{P}-\mathrm{NMR}$ spectra and b $\mathrm{H}_{2}$-TPR of $\mathrm{Al}_{2} \mathrm{O}_{3}-\mathrm{Pt}$ and $\mathrm{Al}_{2} \mathrm{O}_{3}-\mathrm{Pt}-2 \mathrm{P}$ comprising similar particle sizes and different $P$ content
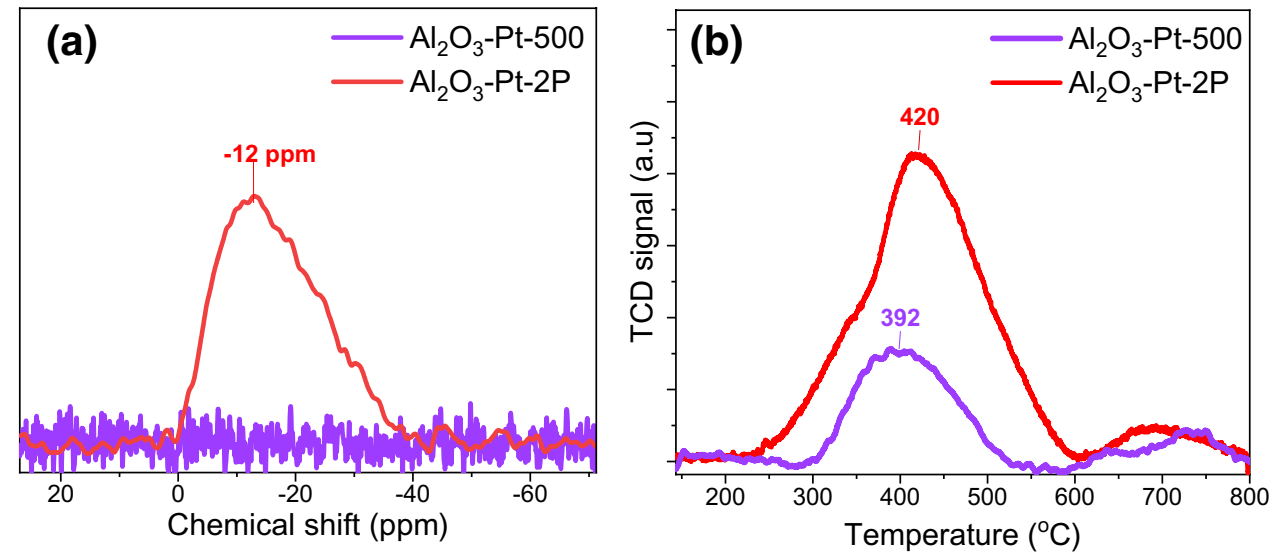
In short, the characterisation data indicated that calcination had no effect on the support but resulted in Pt particle size increase with increasing severity of thermal treatment. The addition of $\mathrm{P}$ lead to the formation of phosphate groups on the alumina support and thus decreased catalyst SA, while $\mathrm{H}_{2}$-TPR suggested that $\mathrm{P}$ also induced changes in $\mathrm{Pt}$ redox properties.

\subsection{Furfural Hydrogenation}

The liquid phase furfural hydrogenation reaction (furfural $0.3 \mathrm{M}$; furfural $/ \mathrm{metal}=1000 \mathrm{~mol} / \mathrm{mol}, 5$ bar $\mathrm{H}_{2}$, in $150^{\circ} \mathrm{C}$ ) was carried out to assess the performance of the different catalysts. Under these reaction conditions, Pt-based catalysts are known to preferentially hydrogenate the $\mathrm{C}=\mathrm{O}$ functional group of furfural and to yield FA, which can in turn be further converted to THFA through hydrogenation of the furan ring (Scheme 1) [33]. In 2-propanol solvent, the formation of FIE through acetal intermediates has also been observed $[10,34]$.

The conversion and selectivity results obtained in the course of $300 \mathrm{~min}$ reaction are shown in Fig. 3. In all samples the furfural conversion increased over time (Fig. 3a). $\mathrm{Al}_{2} \mathrm{O}_{3}-\mathrm{Pt}$ exhibited the highest activity, which decreased in the order: $\mathrm{Al}_{2} \mathrm{O}_{3}-\mathrm{Pt}>\mathrm{Al}_{2} \mathrm{O}_{3}-\mathrm{Pt}-500>\mathrm{Al}_{2} \mathrm{O}_{3}-\mathrm{Pt}-600>\mathrm{Al}_{2} \mathrm{O}_{3}-\mathrm{Pt}-2 \mathrm{P}$. FA was the main reaction product and its selectivity increased during the course of the reaction (Fig. 3b, c). The FA selectivity also decreased in the order: $\mathrm{Al}_{2} \mathrm{O}_{3}-\mathrm{Pt}>\mathrm{Al}_{2} \mathrm{O}_{3}-\mathrm{Pt}-500>\mathrm{Al}_{2} \mathrm{O}_{3}-\mathrm{Pt}-600>\mathrm{Al}_{2} \mathrm{O}_{3}-\mathrm{Pt}-2 \mathrm{P}$. Acetal formation exhibited opposite trends to $\mathrm{FA}$, occurred mostly in the early stages of reaction and was favoured in $\mathrm{Al}_{2} \mathrm{O}_{3}-\mathrm{Pt}-2 \mathrm{P}$. FIE product was also detected and, although the selectivity increased over time, selectivity to FIE was limited to $<5 \%$.
For a direct comparison of the catalytic performance among the samples, Table 1 shows the activity and selectivity values at ca. $50 \%$ furfural conversion. In line with the conversion results in Fig. 3, $\mathrm{Al}_{2} \mathrm{O}_{3}-\mathrm{Pt}$ was highly active and FA was the major product (98.5\%). If we consider the activity of the samples prepared using different calcination procedures, the moles of furfural converted per mole of $\mathrm{Pt}$ decreased with increasing particle size. This is explained by the loss of surface Pt atoms available for reaction as a result of particle growth.

In addition to surface $\mathrm{Pt}$ loss, particle growth also results in different proportion of surface adsorption sites (i.e. increased amount of terrace sites at the expense of edges and corners). To account for possible site effects, the turnover frequency for surface $\mathrm{Pt}\left(\mathrm{TOF}=\mathrm{mol}_{\text {converted }} \bullet \mathrm{mol}_{\mathrm{Ptsurf}^{-1}} \bullet \mathrm{h}^{-1}\right)$ was also determined by taking into account the average particle size derived from TEM, and by assuming hemispherical particles. If the activity were independent on particle morphology and were caused solely by the number of exposed surface Pt atoms, the TOF should remain constant. Nonetheless, Table 1 shows that the TOF increased from 1087 to $26,666 \mathrm{~h}^{-1}$ with increasing average particle size from $\sim 0.6$ to $25 \mathrm{~nm}$, indicating that the Pt surface in larger particles is more active for furfural hydrogenation. Furfural on $\mathrm{Pt}$ is known to adsorb with the furan ring parallel to the metal surface were $\mathrm{C}$ and $\mathrm{O}$ atoms of the carbonyl group bind to $\mathrm{Pt}$ [35]. The increased contribution of terrace sites in larger Pt nanoparticles (discussed thereafter) may favour such configuration explaining the TOF increase after subsequent calcinations of the pristine sample.

Regarding the relationship between particle size and selectivity in Pt-based catalysts, there seem to be no agreement $[12,18-20,36]$ although an increased propensity for decarbonylation has been claimed for particles $<2 \mathrm{~nm}$ in the vapour phase reaction [17]. In our set of catalysts, FA was (a)

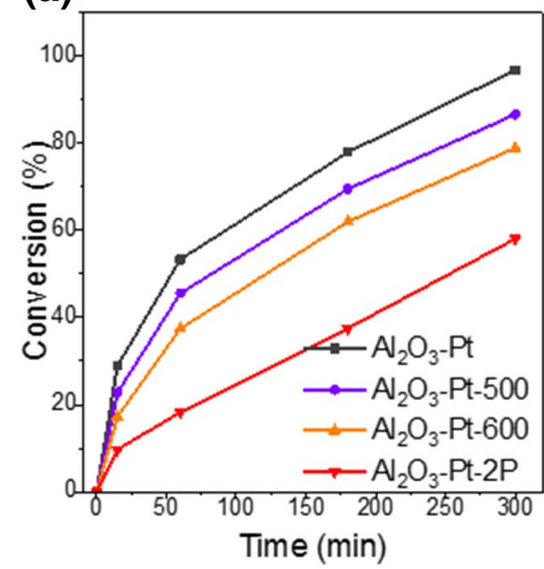

(b)

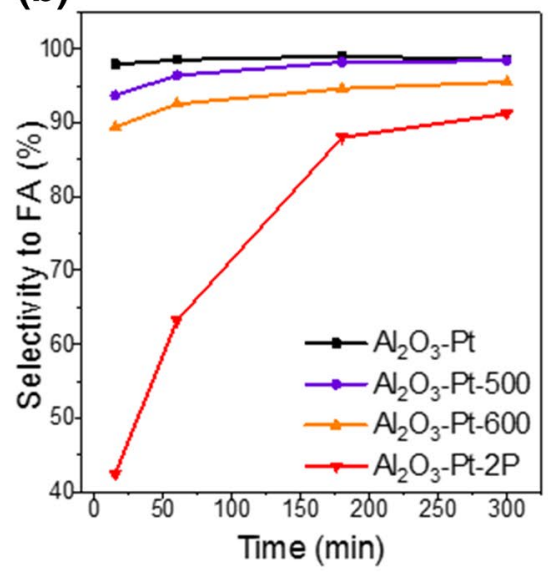

(c)

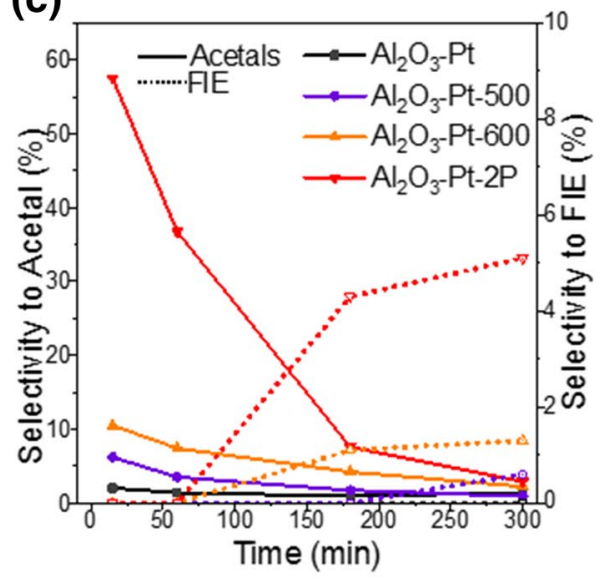

Fig. 3 Activity results obtained during $300 \mathrm{~min}$ of furfural hydrogenation. a Furfural conversion; b selectivity to FA and $\mathbf{c}$ selectivity to acetal and FIE. Conditions: $150{ }^{\circ} \mathrm{C}, 5$ bar $\mathrm{H}_{2}$, furfural $0.3 \mathrm{M}$ in isopropanol, $\mathrm{Pt} /$ furfural $=1 / 1000$ 
always the major product and acetals were the only noticeable by-products (Table 1; Fig. 1). Selectivity appeared to be sensitive to particle size as acetal formation increased slightly with increasing particle size, with the highest selectivity (4.2\%) being reached for $\mathrm{Al}_{2} \mathrm{O}_{3}-\mathrm{Pt}-600$.

Modification of the catalyst by $\mathrm{P}$ resulted in a significant decrease of the for furfural hydrogenation performance. The activity of samples with equivalent particle sizes showed a lower performance in the presence of $\mathrm{P}$ $\left(\mathrm{Al}_{2} \mathrm{O}_{3}-\mathrm{Pt}-2 \mathrm{P}=400 \mathrm{~h}^{-1}\right)$ compared to the P-free catalyst $\left(\mathrm{Al}_{2} \mathrm{O}_{3}-\mathrm{Pt}-500=1883 \mathrm{~h}^{-1}\right)$ pointing to a poisoning effect by this element. While some authors have claimed a promotional effect of P [19-22], deactivation has been also reported [22]. The deactivation observed in our samples could be related to a partial encapsulation of Pt upon $\mathrm{AlPO}_{4}$ formation with the subsequent SA decrease as well as to a coverage of active surface atoms. We cannot exclude that a lower reducibility also contributes to a decreased activity. $\mathrm{P}$ also seemed to affect the selectivity to different reaction products as $\mathrm{Al}_{2} \mathrm{O}_{3}-\mathrm{Pt}-2 \mathrm{P}$ produced undesired acetals (ca. 3\% selectivity) and FIE (ca. 5\%, Fig. 1, Table 1). The conversion of furfural to acetals and ethers is known to require Brønsted acid sites on the alumina surface [37]. Previous reports on $\mathrm{P}$ modified $\mathrm{Ru} / \mathrm{Al}_{2} \mathrm{O}_{3}$ claim that addition of $\mathrm{P}$ generates $\mathrm{Br} ø \mathrm{n}$ sted sites on the support [24]. The formation of FA ether in $\mathrm{Al}_{2} \mathrm{O}_{3}-\mathrm{Pt}-2 \mathrm{P}$ could hence also be related to an increased support acidity. However, this effect might be compensated or affected by the decrease in SA (Table 1).

To better understand the results, the samples were studied by $\mathrm{CO}$ adsorption using DRIFTS (Fig. 4). An inert cordierite with respect to $\mathrm{CO}$ adsorption was also measured and served as reference of gas phase CO signal $\left(2180\right.$ and $\left.2125 \mathrm{~cm}^{-1}\right)$. Beside gas phase $\mathrm{CO}, \mathrm{Al}_{2} \mathrm{O}_{3}-\mathrm{Pt}$ exhibited an intense band at $2051 \mathrm{~cm}^{-1}$ corresponding to the stretch mode of linearly coordinated $\mathrm{CO}\left(\mathrm{v}\left(\mathrm{CO}_{\mathrm{L}}\right)\right)$ on metallic Pt sites. Several sites contribute to this band such as close packed $\left(\begin{array}{lll}1 & 1 & 1\end{array}\right)$ terrace sites (ca. $2090 \mathrm{~cm}^{-1}$ ), less dense packed terraces ( 100 )

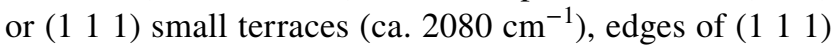

terraces (ca. $2065 \mathrm{~cm}^{-1}$ ), and kinks (ca. $2040 \mathrm{~cm}^{-1}$ ) [38-44]. Note that the position of the bands is also influenced by the Pt oxidation state as a blue shift is usually reported for nanoparticles with decreased electron density (i.e. more oxidic character) [45-47]. An additional weaker band was present between 1900 and $1700 \mathrm{~cm}^{-1}$, which is due to bridge-bonded $\mathrm{CO}\left(\mathrm{v}\left(\mathrm{CO}_{\mathrm{B}}\right)\right)$ on $\mathrm{Pt}[38,41,44]$.

For the set of samples prepared with different thermal treatments, the intensity of all bands decreased with increasing particle size consistent with the loss of surface $\mathrm{Pt}$ atoms upon particle sintering (Fig. $4 \mathrm{a}$ ). $\mathrm{Al}_{2} \mathrm{O}_{3}-\mathrm{Pt}, \mathrm{Al}_{2} \mathrm{O}_{3}-\mathrm{Pt}-500$ and $\mathrm{Al}_{2} \mathrm{O}_{3}-\mathrm{Pt}-600$ show maximum intensity of the $\mathrm{v}\left(\mathrm{CO}_{\mathrm{L}}\right)$ band at similar frequency (ca. $2052 \mathrm{~cm}^{-1}$ ) suggesting strong contribution from edge and kinks to the signal. A shoulder at higher wavenumbers is also observed in these three samples. Such shoulder blue shifted from $2079 \mathrm{~cm}^{-1}$ in $\mathrm{Al}_{2} \mathrm{O}_{3}-\mathrm{Pt}$ to 2084 and $2090 \mathrm{~cm}^{-1}$ in $\mathrm{Al}_{2} \mathrm{O}_{3}-\mathrm{Pt}-500$ and $\mathrm{Al}_{2} \mathrm{O}_{3}-\mathrm{Pt}-600$, respectively. We attribute this shift to an increasing contribution of terrace sites on larger Pt particles. This is especially the case for $\mathrm{Al}_{2} \mathrm{O}_{3}-\mathrm{Pt}-600$, which undergoes significant sintering and exhibits a distinctive band at $2090 \mathrm{~cm}^{-1}$ corresponding to packed terrace sites.

DRIFTS spectra of $\mathrm{Al}_{2} \mathrm{O}_{3}-\mathrm{Pt}-500$ and $\mathrm{Al}_{2} \mathrm{O}_{3}-\mathrm{Pt}-2 \mathrm{P}$, which comprised equivalent particle size (Fig. 4b), show that the intensity of the signals of adsorbed $\mathrm{CO}$ decreased significantly in the $\mathrm{P}$ containing sample. Considering the decrease in SA and $\mathrm{AlPO}_{4}$ formation (Table 1; Fig. 4a), it is likely that the $\mathrm{CO}$ adsorption decrease was caused by the loss of Pt atoms induced by Pt encapsulation/blockage phenomena. In addition, a blue shift of $\mathrm{v}\left(\mathrm{CO}_{\mathrm{L}}\right)$ from 2052 to $2061 \mathrm{~cm}^{-1}$ was also observed for $\mathrm{Al}_{2} \mathrm{O}_{3}-\mathrm{Pt}-2 \mathrm{P}$. As these two samples comprise equivalent particle size, we believe that the shift of $v\left(\mathrm{CO}_{\mathrm{L}}\right)$ to higher wavenumbers originates from the decreased electron density of the Pt particles induced by the presence of $\mathrm{P}$ on the $\mathrm{Al}_{2} \mathrm{O}_{3}$ support and tentatively, near the Pt particles [47]. This conclusion is also supported by $\mathrm{H}_{2}$-TPR profiles (Fig. 2b), which suggested a higher fraction of PtOx and decreased reducibility in the presence of $\mathrm{P}$.
Fig. 4 DRIFTS spectra of adsorbed CO on Pt-based catalysts; a samples prepared with different thermal treatments and b samples with equivalent particle size with and without $\mathrm{P}$
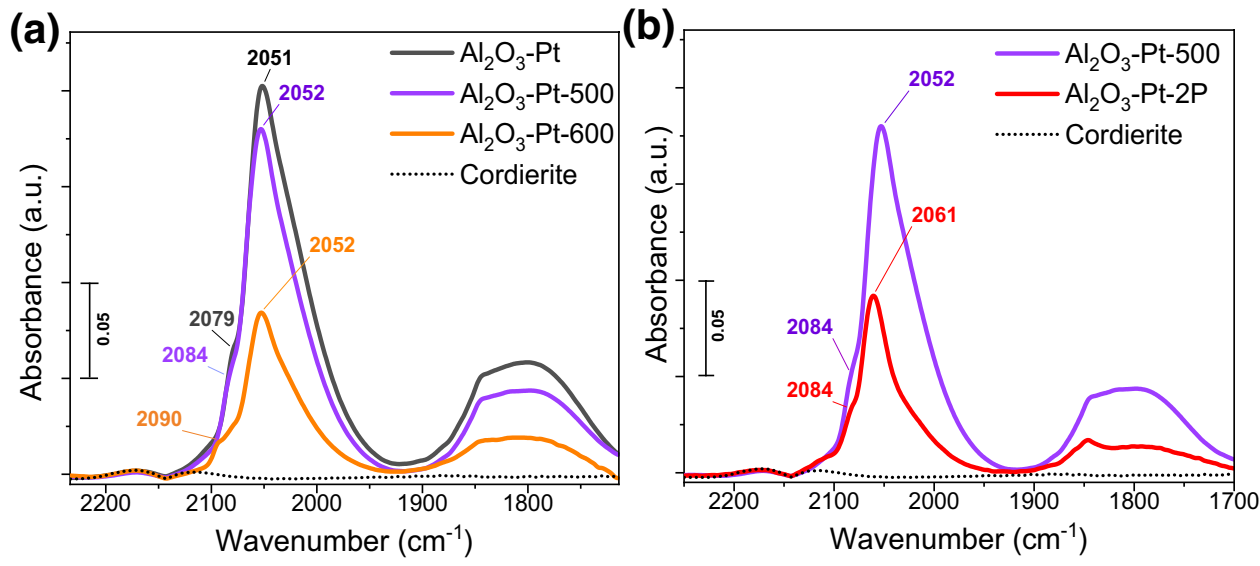


\subsection{Durability Test on $\mathrm{Al}_{2} \mathrm{O}_{3}-\mathrm{Pt}$}

While noble metal-based materials are desirable for their high activity towards furfural hydrogenation [33], the natural scarcity of noble metals and their high price call for the development of stable catalysts to the reaction environment. In this regards, $\mathrm{Al}_{2} \mathrm{O}_{3}-\mathrm{Pt}$ was chosen for the evaluation of catalyst durability by performing five consecutive activity cycles. After every run, the sample was recovered by centrifugation and was reused in the subsequent test. The reaction solution was recovered for measuring conversion and selectivity as well as to account for potential Pt leaching (ICP-OES). Activity results in Fig. 5 show that conversion gradually decreased after each run from ca. 95\% (first run) to $79 \%$ (fifth run), while selectivity to FA remained relatively constant at $95-98 \%$.

Several effects can contribute to the observed deactivation. In spite of the TOF increase, the overall catalytic activity decreased upon Pt sintering driven by the loss of active surface (Table 1). In addition, blockage of active sites by irreversible adsorption of reaction intermediates as well as noble metal leaching can also occur during reaction [7]. To determine the causes of deactivation over consecutive furfural hydrogenation runs, pristine $\mathrm{Al}_{2} \mathrm{O}_{3}-\mathrm{Pt}$ was characterised before and after the durability test.

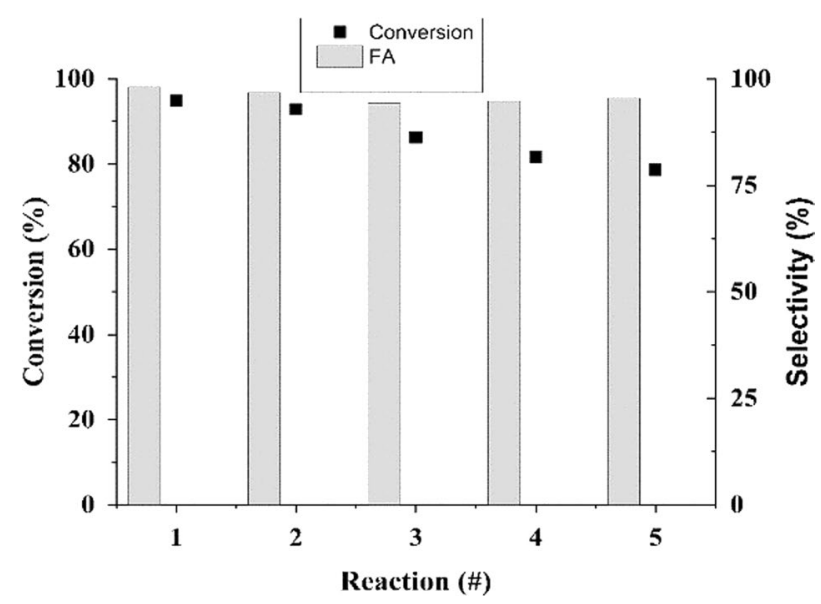

Fig. 5 Furfural conversion and FA selectivity over $\mathrm{Al}_{2} \mathrm{O}_{3}-\mathrm{Pt}$ during five consecutive cycles of furfural hydrogenation. Reaction conditions: $150{ }^{\circ} \mathrm{C}, 5$ bar of $\mathrm{H}_{2}$, furfural $0.3 \mathrm{M}$ in isopropanol, $\mathrm{Pt} /$ furfural $=1 / 1000$, reaction time $5 \mathrm{~h}$
ICP-OES revealed that the Pt content decreased from 0.99 to $0.72 \mathrm{wt} \%$ after the durability test. As the analysis of the liquid phase recovered after reaction evidenced no Pt leaching, the decreased noble metal content can be attributed to a sample dilution effect due to accumulation of adsorbed species. TEM images revealed that significant Pt sintering occurred during the consecutive activity cycles (Fig. 6). The pristine sample exhibited a narrow particle size distribution with average particle size of $0.6 \mathrm{~nm}$, while after durability test a broader particle size distribution with average particle size of ca. $2.0 \mathrm{~nm}$ was obtained. The intensity of $\mathrm{v}\left(\mathrm{CO}_{\mathrm{L}}\right)$ and $\mathrm{v}\left(\mathrm{CO}_{\mathrm{B}}\right)$ bands in the DRIFT spectra of adsorbed $\mathrm{CO}$ decreased significantly after the activity cycles (Fig. 7) indicating loss of active surface, in agreement with the particle size increase observed by TEM in Fig. 6. Note however that the intensity of the spectrum of $\mathrm{Al}_{2} \mathrm{O}_{3}-\mathrm{Pt}$-used (average particle size of $2 \mathrm{~nm}$ ) was lower than that of $\mathrm{Al}_{2} \mathrm{O}_{3}-\mathrm{Pt}-600$ ( $25 \mathrm{~nm}$, see DRIFTS in Fig. 4a); thus, sintering alone cannot explain the strong signal intensity loss in the samples exposed to consecutive durability tests. Besides, a blue shift of the main adsorption peak to $2062 \mathrm{~cm}^{-1}$ upon the durability test suggested that additional phenomena took place during reaction. A plausible explanation was given in previous studies from some of the authors using Pd-based catalysts, where irreversible adsorption of furfural and reaction products lead to blockage of active surface, thus compromising activity [7].

To investigate the presence of reaction products, $\mathrm{Al}_{2} \mathrm{O}_{3}-\mathrm{Pt}$ was investigated by ATR-IR before and after activity cycles (Fig. 8). In the C-H stretching region (3000-2800 $\mathrm{cm}^{-1}$, Fig. 8a) no bands were observed for the catalyst before reaction, while the used sample revealed peaks at 2923, 2973 and $2852 \mathrm{~cm}^{-1}$. These peaks can be ascribed to the $\mathrm{v}(\mathrm{C}-\mathrm{H})$ of $\mathrm{CH}$ and $\mathrm{CH}_{2}$ groups [48]. Similarly, signals in the $\mathrm{C}=\mathrm{O}$ and $\mathrm{C}=\mathrm{C}$ vibrational region (Fig. $8 \mathrm{~b}$ ) were only detected in the sample used for the durability test, where the broad envelope between 1700 and $1500 \mathrm{~cm}^{-1}$ can be ascribed to $\mathrm{C}=\mathrm{C}$ stretching vibrations of chemisorbed reaction products while bands at 1270 and $1140 \mathrm{~cm}^{-1}$ can be associated with -C-O- groups [49]. These signals indicated the presence of fragments of reactants and decomposition intermediates adsorbed on the catalyst surface, which can contribute to catalyst deactivation. 
Fig. 6 Selected HAADF-STEM images of $\mathrm{Al}_{2} \mathrm{O}_{3}-\mathrm{Pt}$ taken a before and $\mathbf{b}$ after five consecutive cycles of furfural hydrogenation. $\mathbf{c}$ and $\mathbf{d}$ Corresponding particle size distributions
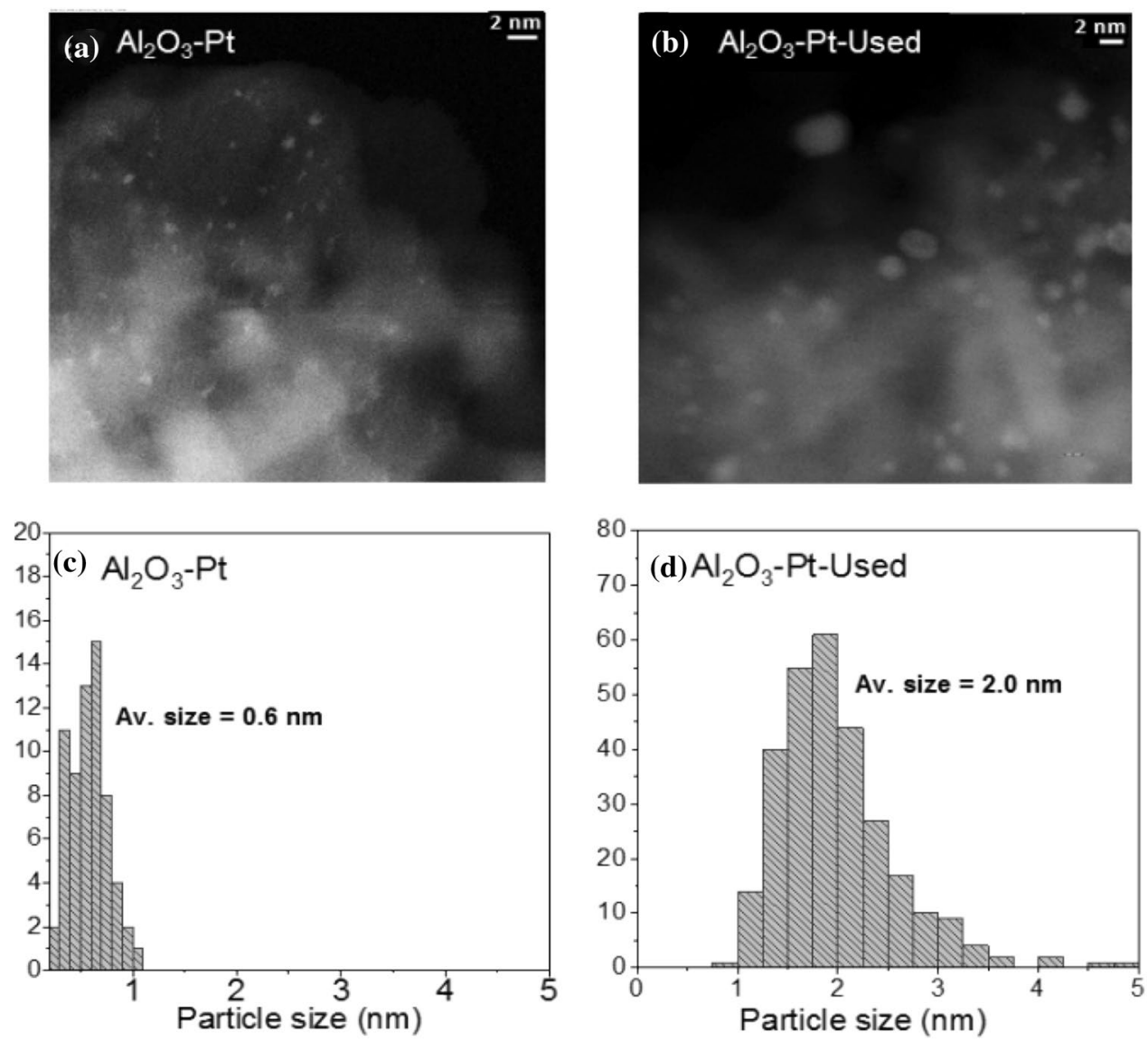

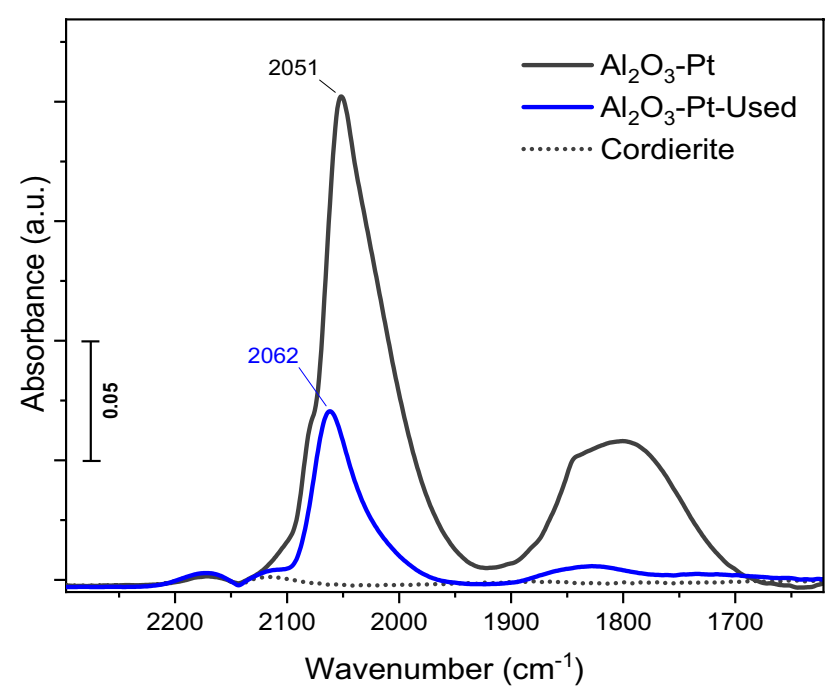

Fig. 7 DRIFTS spectra of adsorbed $\mathrm{CO}$ on $\mathrm{Al}_{2} \mathrm{O}_{3}-\mathrm{Pt}$ before and after five consecutive cycles of furfural hydrogenation

\section{Conclusions}

A set of catalysts consisting of $\mathrm{Al}_{2} \mathrm{O}_{3}$ supported Pt was studied for furfural hydrogenation. Evaluation of samples prepared with different thermal treatments showed that a relation exists between Pt particle size and catalyst performance. The overall drop in activity upon Pt sintering was related to the loss of noble metal surface available for reaction (i.e. decrease of Pt surface/bulk ratio). Nonetheless, the TOF for the number of surface Pt atoms indicated that compared with small particles, atoms on large particles (ca. $25 \mathrm{~nm}$ ) exhibiting a higher proportion of terrace sites are more active towards furfural hydrogenation.

Addition of $2 \mathrm{wt} \%$ of phosphorous to $\mathrm{Pt} / \mathrm{Al}_{2} \mathrm{O}_{3}$ was detrimental for furfural hydrogenation. The observed $\mathrm{AlPO}_{4}$ formation and the loss of surface area suggested that Pt nanoparticle encapsulation and blockage of active sites are the cause of catalyst deterioration. This was supported by $\mathrm{CO}$ 
Fig. 8 Ex-situ ATR-IR spectra of $\mathrm{Al}_{2} \mathrm{O}_{3}-\mathrm{Pt}$ before and after five consecutive cycles of furfural hydrogenation
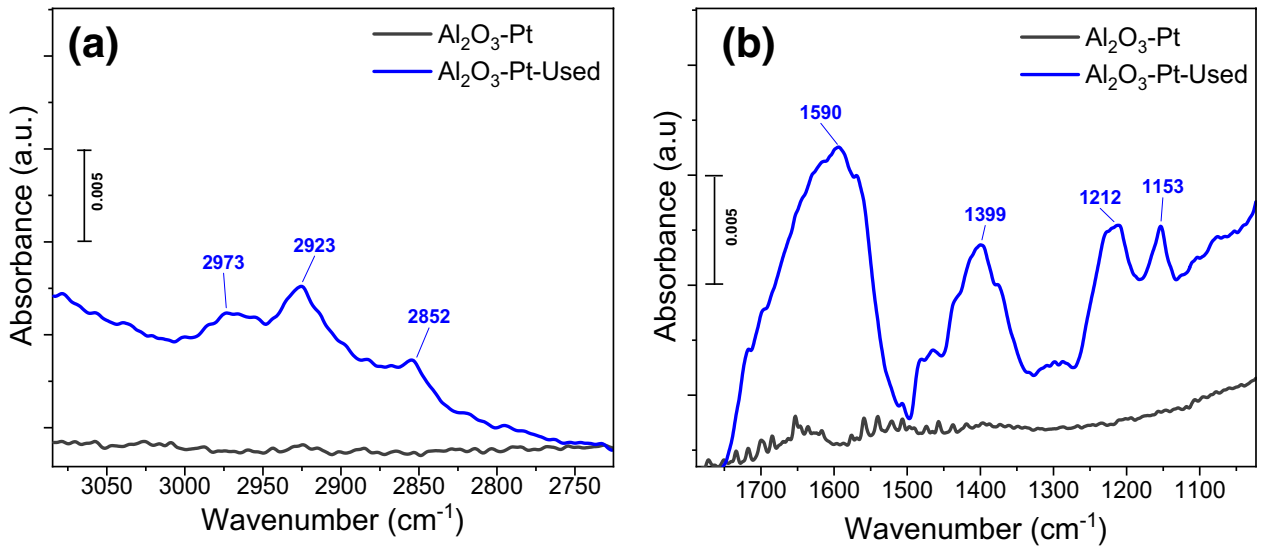

adsorption, which showed that for equivalent Pt particle size, an increasing phosphorous content inhibited $\mathrm{CO}$ adsorption. Furthermore, the presence of phosphorous lead to the formation of undesirable FA ether and acetals at the expenses of FA, which was attributed to the increased acidity of the catalyst upon phosphorous treatment.

Durability tests on the most active sample revealed a significant loss of activity by ca. $15 \%$ over five consecutive activity cycles. The subsequent characterisation allowed attributing the deactivation to two effects: noble metal sintering and blockage of active surface by the irreversible adsorption of furfural and reaction intermediates.

Acknowledgements The authors acknowledge the financial support from the Swiss Innovation Agency (Innosuisse) and PSI. The authors also thank Dr. F. Krumeich, Dr. D. Rentsch as well as Ms. V. Jacobsen for their assistance with TEM, NMR and $\mathrm{H}_{2}$-TPR measurements, respectively.

Funding Open Access funding provided by Lib4RI - Library for the Research Institutes within the ETH Domain: Eawag, Empa, PSI \& WSL. This work was supported by Innosuisse - Schweizerische Agentur für Innovationsförderung.

Open Access This article is licensed under a Creative Commons Attribution 4.0 International License, which permits use, sharing, adaptation, distribution and reproduction in any medium or format, as long as you give appropriate credit to the original author(s) and the source, provide a link to the Creative Commons licence, and indicate if changes were made. The images or other third party material in this article are included in the article's Creative Commons licence, unless indicated otherwise in a credit line to the material. If material is not included in the article's Creative Commons licence and your intended use is not permitted by statutory regulation or exceeds the permitted use, you will need to obtain permission directly from the copyright holder. To view a copy of this licence, visit http://creativecommons.org/licenses/by/4.0/.

\section{References}

1. Chen B, Li F, Huang Z, Yuan G (2015) Appl Catal A 500:13
2. Huang R, Cui Q, Yuan Q, Wu H, Guan Y, Wu P (2018) ACS Sustain Chem Eng 6:6957

3. Mariscal R, Maireles-Torres P, Ojeda M, Sádaba I, López-Granados M (2016) Energy Environ Sci 9:1144

4. Rogers SM, Catlow CRA, Chan-Thaw CE, Chutia A, Jian N, Palmer RE, Perdjon M, Thetford A, Dimitratos N, Villa A, Wells PP (2017) ACS Catal 7:2266

5. Machado G, Leon S, Santos F, Lourega R, Dullius J, Mollmann ME, Eichler P (2016) Nat Resour 7:115

6. Salnikova KE, Matveeva VG, Larichev YV, Bykov AV, Demidenko GN, Shkileva IP, Sulman MG (2019) Catal Today 329:142

7. Alijani S, Capelli S, Cattaneo S, Schiavoni M, Evangelisti C, Mohammed KMH, Wells PP, Tessore F, Villa A (2020) Catalysts 10:1

8. Liu L, Lou H, Chen M (2018) Appl Catal A 550:1

9. Liu L, Lou H, Chen M (2016) Int J Hydr En 41:14721

10. Wang Y, Cui Q, Guan Y, Wu P (2018) Green Chem 20:2110

11. Ma R, Wu XP, Tong T, Shao ZJ, Wang Y, Liu X, Xia Q, Gong XQ (2017) ACS Catal 7:333

12. Bhogeswararao S, Srinivas D (2015) J Catal 327:65

13. Liu F, Liu Q, Xu J, Li L, Cui YT, Lang R, Li L, Su Y, Miao S, Sun H, Qiao B, Wang A, Jérôme F, Zhang T (2018) Green Chem 20:1770

14. Zhou X, Feng Z, Guo W, Liu J, Li R, Chen R, Huang J (2019) Ind Eng Chem Res 58:3988

15. Meng X, Yang Y, Chen L, Xu M, Zhang X, Wie M (2019) ACS Catal 9:4226

16. Taylor MJ, Durndell LJ, Isaacs MA, Parlett CMA, Wilson K, Lee AF, Kyriakou G (2016) Appl Catal B 180:580

17. Ramirez-Barria C, Isaacs M, Wilson K, Guerrero-Ruiz A, Rodríguez-Ramos I (2018) Appl Catal A 563:177

18. Maligal-Ganesh RV, Xiao C, Goh TW, Wang LL, Gustafson J, Pei Y, Qi Z, Johnson DD, Zhang S, Tao F, Huang W (2016) ACS Catal 6:1754

19. Castelbou JL, Szeto KC, Barakat W, Merle N, Godard C, Taoufik M, Claver C (2017) Chem Com 53:3261

20. Wang C, Guo Z, Yang Y, Chang J, Borgna A (2014) Ind Eng Chem Res 53:11284

21. Pushkarev VV, Musselwhite N, An K, Alayoglu S, Somorjai GA (2015) Nano Lett 12:5196

22. Mallat T, Brönnimann C, Baiker A (1997) Appl Catal A 149:103

23. Belykh L, Skripov N, Stepanova T, Akimov V, Tauson V, Schmidt F (2014) Curr Nanosci 11:175

24. Fovanna T, Campisi S, Villa A, Kambolis A, Peng G, Rentsch D, Kröcher O, Nachtegaal M, Ferri D (2020) RSC Adv 10:11507 
25. Sampath A, Flaherty DW (2020) Catal Sci Technol 10:993

26. Witzke ME, Almithn A, Coonrod CL, Triezenberg MD, Hibbitts DD, Flaherty DW (2019) J Am Chem Soc 141:16671

27. Schindelin J, Arganda-Carreras I, Frise E, Kaynig V, Longair M, Pietzsch T, Preibisch S, Rueden C, Saalfeld S, Schmid B, Tinevez JY, White DJ, Hartenstein V, Eliceiri K, Tomancak P, Cardona A (2012) Nat Methods 9:676

28. Hansen TK, Høj M, Hansen BB, Janssens TVW, Jensen AD (2017) Top Catal 60:1333

29. Rokosz MJ, Chen AE, Lowe-Ma CK, Kucherov AV, Benson D, Peck MCP, McCabe RW (2001) Appl Catal B 33:205

30. Resende NS, Eon JG, Schmal M (1999) J Catal 13:6

31. Bergman SL, Granestrand J, Xi S, Du Y, Tang Y, Tang C, Kienkas L, Pettersson LJ, Bernasek SL (2020) J Phys Chem C 124:2945

32. Agote-Arán M, Elsener M, Schütze FW, Schilling CM, Sridhar M, Katsaounis E, Kröcher O, Ferri D (2021) Appl Catal B 291:120062

33. Wang Y, Zhao D, Rodríguez-Padrón D, Len C (2019) Catalysts 9:796

34. Mertens PGN, Cuypers F, Vandezande P, Ye X, Verpoort F, Vankelecom IFJ, De Vos DE (2007) Appl Catal A 325:130

35. Tsatsos S, Ladas S, Kyriakou G (2020) J Phys Chem C $124: 26268$

36. Wang C, Luo J, Liao V, Lee JD, Onn TM, Murray CB, Gorte RJ (2018) Catal Today 302:73

37. Padovan D, Al-Nayili A, Hammond C (2017) Green Chem 19:2846

38. Primet M, Basset JM, Mathieu MV, Prettre M (1973) J Catal $29: 213$
39. Klünker C, Balden M, Lehwald S, Daum W (1996) Surf Sci 360:104

40. Brummel O, Waidhas F, Faisal F, Fiala R, Vorokhta M, Khalakhan I, Dubau M, Figueroba A, Kovács G, Aleksandrov HA, Vayssilov GN, Kozlov SM, Neyman KM, Matolín V, Libuda J (2016) J Phys Chem C 120:19723

41. Xu J, Yates JT (1995) Surf Sci 327:193

42. Anderson JA (1992) Catal Lett 13:363

43. De La Cruz C, Sheppard N (1994) Acta Part A 50:271

44. Rivallan M, Seguin E, Thomas S, Lepage M, Takagi N, Hirata H, Thibault-Starzyk F (2010) Angew Chem Int Ed 49:785

45. Gänzler AM, Lichtenberg H, Frenkel AI, Casapu M, Boubnov A, Wang D, Grunwaldt JD (2016) J Phys Conf Ser 712:012045

46. Chilukoti S, Gao F, Anderson BG, Niemantsverdriet JWH, Garland M (2008) Phys Chem Chem Phys 10:5510

47. Riguetto BA, Damyanova S, Gouliev G, Marques CMP, Petrov L, Bueno JMC (2004) J Phys Chem B 108:5349

48. Pang SH, Schoenbaum CA, Schwartz DK, Medlin JW (2013) Nat Commun 4:1

49. Shao Y, Hu X, Zhang Z, Sun K, Gao G, Wei T, Zhang S, Hu S, Xiang J, Wang Y (2019) Green Energy Environ 4:400

Publisher's Note Springer Nature remains neutral with regard to jurisdictional claims in published maps and institutional affiliations. 